\title{
ABO blood groups as a new potential predictive factor in radiotherapy hematological changes
}

\author{
Seyfizadeh $\mathrm{N}^{1}$, Saboori $\mathrm{H}^{2}$, Borzoueisileh $\mathrm{S}^{3}$, Habibi $\mathrm{M}^{4}$, Elahimanesh $\mathrm{F}^{2}$ \\ Faculty of Paramedical Science, Kurdistan University of Medical Sciences, Sanandaj, Iran. \\ faridehelahimanesh@gmail.com
}

\begin{abstract}
AIM: Cancer treatments specially with new high Tec radiotherapy equipment's calling daily progression in method and predictive factors affecting treatment goals. Due to important effect of oxygen on cells radio sensitivity, tumor blood circulation and it's antigens like ABO blood groups maybe an important predictive factor for radiotherapy response and it is adverse events. The aim of this study was the assessment of the hematological manifestations of local radiotherapy and association with ABO blood groups.

METHODS: In this observational study, $2 \mathrm{ml}$ of peripheral blood were taken from 152 patients with routine $3 \mathrm{D}$ conformal radiotherapy treatment course and the blood parameters achieve and documented at four stage during treatment courses. The data were analyzed by repeated measurement andone-way ANOVA.

RESULTS: Statistically significant reductions of the platelets, white blood cells (WBC), and lymphocytes counts were demonstrated. Also an increased percentage of polymorphonuclear cells during local radiotherapy exposure was found. The changes in WBC counts were observed to be in association with $A B O$ blood groups. The other evaluated factors were not significantly associated with ABO blood groups. CONCLUSIONS: Our results showed an association between radiotherapy patients ABO blood groups and some hematological changes in their blood circulation (Fig. 7, Ref. 23). Text in PDF www.elis.sk. KEY WORDS: ABO blood group, local radiotherapy, hematological parameters, individual radiotherapy, predictive factor.
\end{abstract}

\section{Introduction}

Radiotherapy (RT) has a critical role in local cancer treatments (1-3). Significant progress was achieved in RT over recent decades (4). The improvements in intensity modulation, delineation of the organs at risk, application of new regimens and other improvements led to an increase in the application and accuracy of this modality in cancer treatment that in working to gather calling for improvements in denotation of new predictive factors affecting patient quality of life and his/her treatment accuracy $(4,5)$.

Because of increases in life expectancy and advances in RT application, the late adverse effects of radiotherapy are more important and may reduce the RT efficacy $(6,7)$. Reports indicated that RT has also biological effects, outside of the treatment field which are known as systematic effects (1).

\footnotetext{
${ }^{1}$ Stem Cell Research Center, Tabriz University of Medical Sciences, Tabriz, Iran, and Student Research Committee, Tabriz University of Medical Sciences, Tabriz, Iran, ${ }^{2}$ Department of radiotherapy, Faculty of Paramedical Science, Kurdistan University of Medical Sciences, Sanandaj, Iran, ${ }^{3}$ Cellular and Molecular Research Center, Yasuj University of Medical Sciences, Yasuj, Iran, and ${ }^{4}$ Department of Radiotherapy, Faculty of Paramedical Science, Tehran University of Medical Sciences, Tehran, Iran

Address for correspondence: F.Elahimanesh, Department of Radiology, Faculty of Paramedical Science, Kurdistan University of Medical Sciences, Sanandaj, Iran.
}

Peripheral blood cell counts reversely correlate with the received radiation dose, and their reduced levels are seen during and after treatment (8). Lymphocytes are one of the most radiosensitive cells, and their counts will decrease after irradiation (9). Because of the importance of helper and cytotoxic cells as subsets of lymphocyte in immune responses to tumor and infection, the changes in the counts and function of Lymphocytes cells could affect anti-tumor immunity (9).

Red blood cells (RBCs) are more resistant than lymphocytes, but the exposure to radiation at high doses of radiotherapy could change their membrane shear elastic modulus and viscosity (10).

Some reports indicated an increase in the recurrence rates of anemia after radiation therapy (11). The hemoglobin (HB) level modifier could change tissue oxygenation in vivo (12). Oxygen is one of the most important radio sensitizers, and hypoxic tumor cells are most susceptible cells in tumor recurrence which affect the prognosis of the treatment. Some researchers reported a relation between $\mathrm{HB}$ and arterial oxygen content with tumor oxygenation (13). Some studies have suggested a relation between ABO blood group and risk of certain cancers and they have indicated that $\mathrm{ABO}$ blood group could be a risk factor for some cancers $(14,15)$.

Furthermore, the blood cell and parameter changes could affect the treatment outcomes (16). Because of the fact that oxygenation is one of the most important parameters which influences the cancerous cells in radiotherapy, the changes in blood parameters 

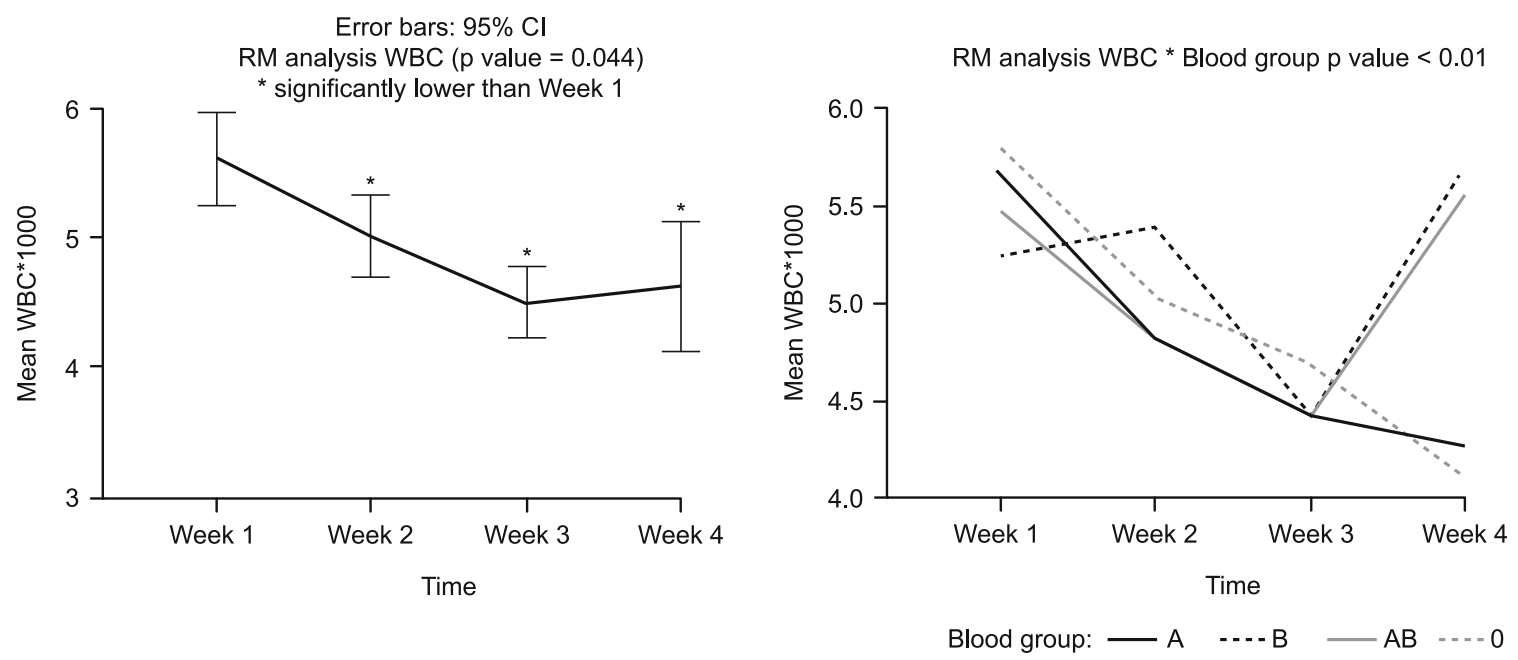

Fig. 1. The changes of WBC count during fourweeksevaluation (left) and its association with ABO blood group (right)

which affect tissue oxygenation could be important as a predictive factor of radio sensitivity in individual radiotherapy $(17,18)$. Thus the purpose of this study was to assess the blood parameter changes during local radiotherapy and to examine whether these changes are associated with $\mathrm{ABO}$ blood groups.

\section{Materials and Methods}

\section{Study population and irradiation}

The study population was 152 cancer patients referred to Tohid hospital of Sanandaj, Iran, from 2011 to 2016. Informed consents were obtained from all the donors and their demographic information was collected. The simulations were done by GE LightSpeed RT 16 CT Scanner, and the irradiation was performed by Elekta Synergy platform system $(10 \mathrm{MeV})$. As their routine treatment course, at the first week of radiotherapy, $2 \mathrm{ml}$ of peripheral blood were taken in anticoagulant tubes. At the next three stages, this process was repeated every week, and blood parameters were measured.

\section{Blood cell counts and parameters}

The blood group was determined in the laboratory at the first stage, then the counts of RBC and white blood cells (WBC), platelet (PLT), lymphocytes (Lymph), polymorphonuclear (PMN) percentage and also their HB and Hematocrit (HCT) level were measured by an automatic analyzer. These variables were analyzed weekly until the end of radiotherapy course.

\section{Statistical analysis}

The obtained data were analyzed by repeated measurement and one-way ANOVA using SPSS 16 software. A p less than 0.05 was considered as significant.

The study was approved by ethical committee of Kurdistan University of Medical Sciences.

\section{Results}

From 152 individuals who participated in this study, 117 subjects were female, and 35 were male. The prospective mean age \pm $\mathrm{SD}$ was $54.05 \pm 14.55$. The blood group of $36.4 \%$ of donors was $\mathrm{A}$, and $23.8 \%, 12.6 \%, 27.2 \%$ had $\mathrm{B}, \mathrm{AB}$, and $\mathrm{O}$ blood group, respectively. The accumulated radiotherapy dose was between 30 and 70 Gy with the mean \pm SD of $49.51 \pm 9.44$ and the dose per fraction was $202.38 \pm 39.83$ ( $18-300 \mathrm{cGy})$. The applied radiation fields were between 1 to $4,1.1 \%$ had one field, $34.8 \%, 20.2 \%$, and $43.8 \%$ had 2,3 , and four radiation fields, respectively. The number of the fractions was between 10 and 39 .

\section{WBC, RBC and PLT counts}

A repeated ANOVA measurements with a Greenhouse-Geisser correction showed that the WBC counts during radiation therapy were significantly $(\mathrm{p}=0.044)$ associated with time. Also, the association between WBC count and blood group with time was statistically $(p=0.004)$ significant (Fig. 1). The repeated measurements analysis of WBC counts in different blood groups showed that it was statistically significant only in A and $\mathrm{O}$ blood group ( $\mathrm{p}<0.001)$. There is no significant $(\mathrm{p}=0.332)$ change in RBC counts during the follow-up period (Fig. 2). Also, there is no significant association $(\mathrm{p}=0.344)$ between $\mathrm{RBC}$ counts and ABO blood groups with time course. PLT counts significantly decreased $(p<0.001)$ during radiation therapy. But, the effect of Blood group on PLT count during evaluation time course was not statistically $(p=0.641)$ significant (Fig. 3$)$. Data showed that the PLT in week one is significantly higher than other three weeks, two $(p=0.003)$, three $(p<0.005)$ and four $(p=0.001)$. The mean of PLT count of each blood group was not significantly different with other blood groups in the same week. All data is presented in Figure 1. 

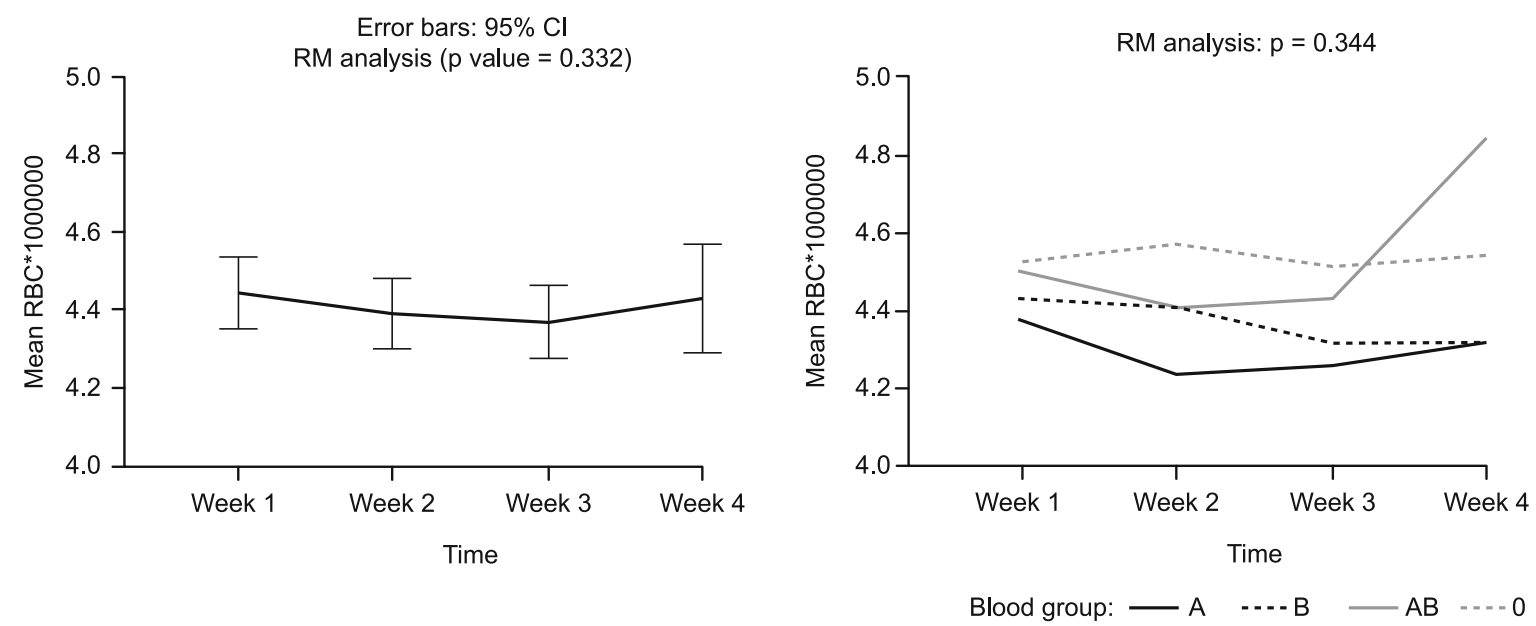

Fig. 2. The changes of RBC count during fourweeks evaluation (left) and its association with ABO blood group (right)
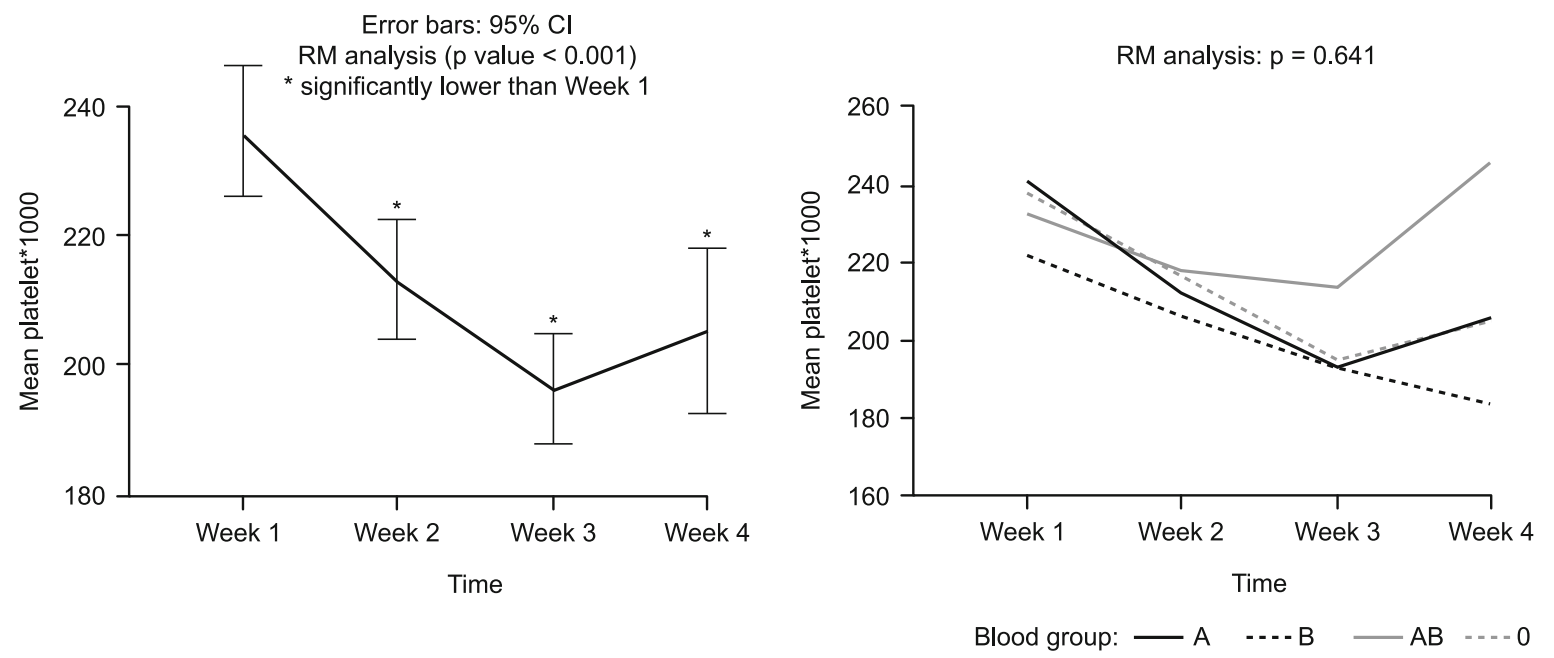

Fig. 3. The changes of PLT count during four weeks evaluation (left) and its association with ABO blood group (right)
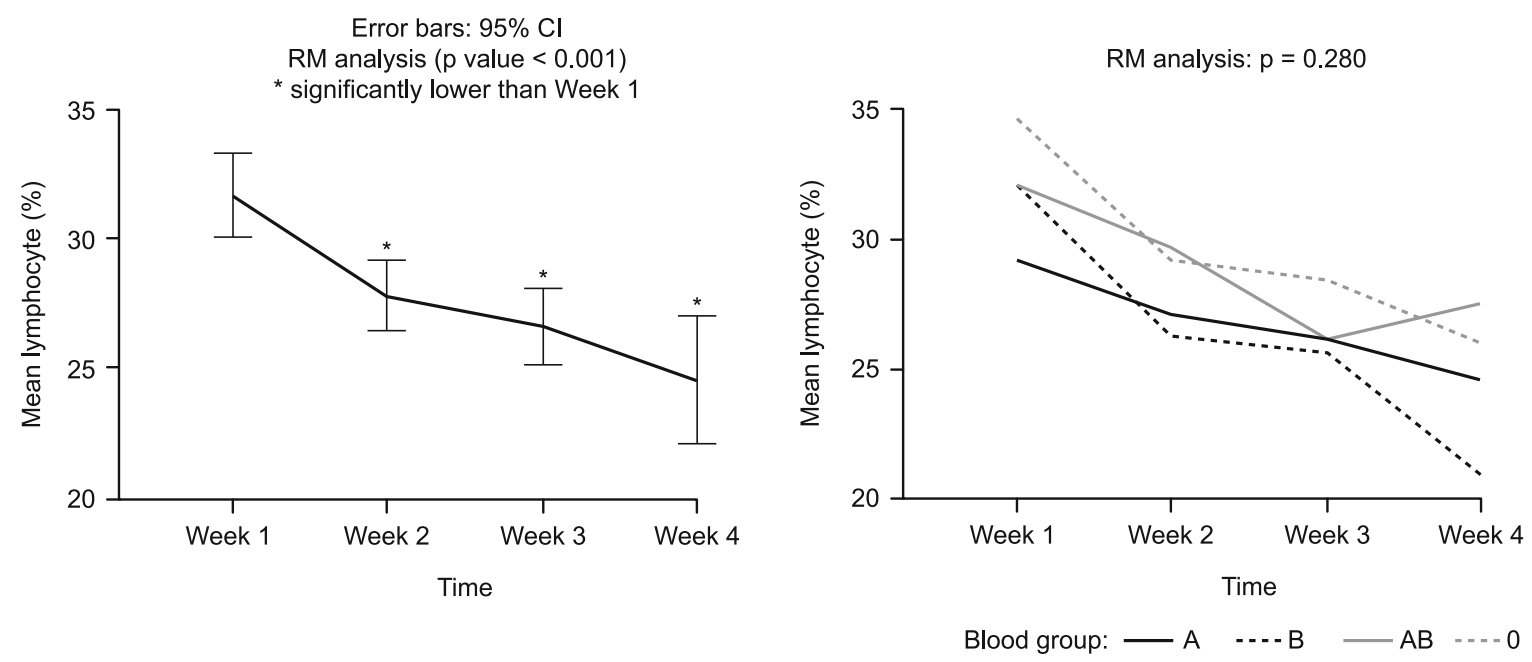

Fig. 4. The changes of Lymph percentage during fourweeksevaluation (left) and its association with ABO blood group (right) 
Error bars: $95 \% \mathrm{Cl}$

RM analysis $(p$ value $=0.167)$

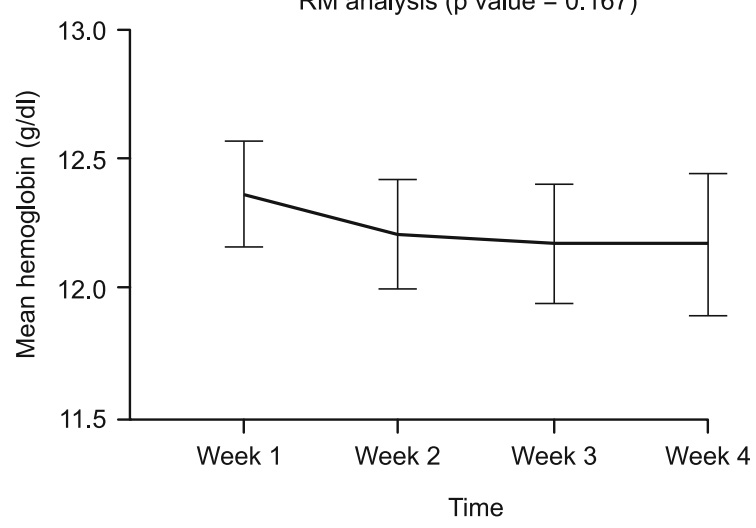

RM analysis: $p=0.236$

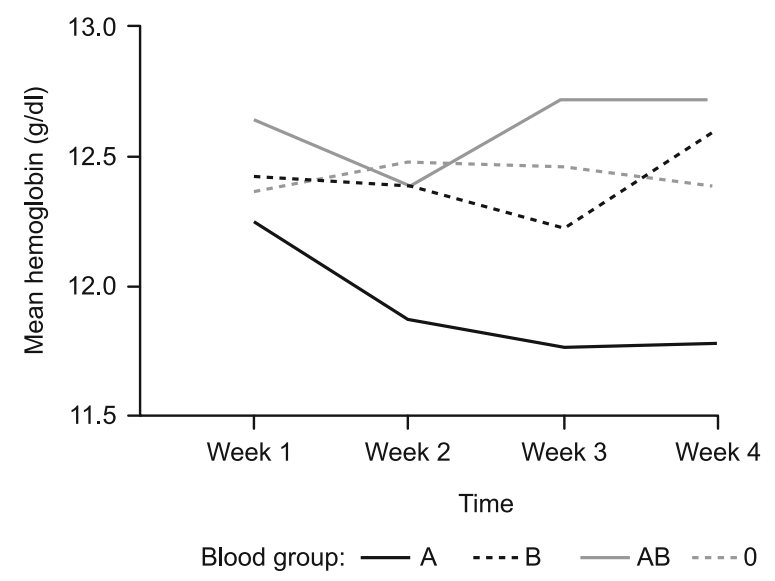

Fig. 5. The changes of HB level during fourweeksevaluation (left) and its association with ABO blood group (right)
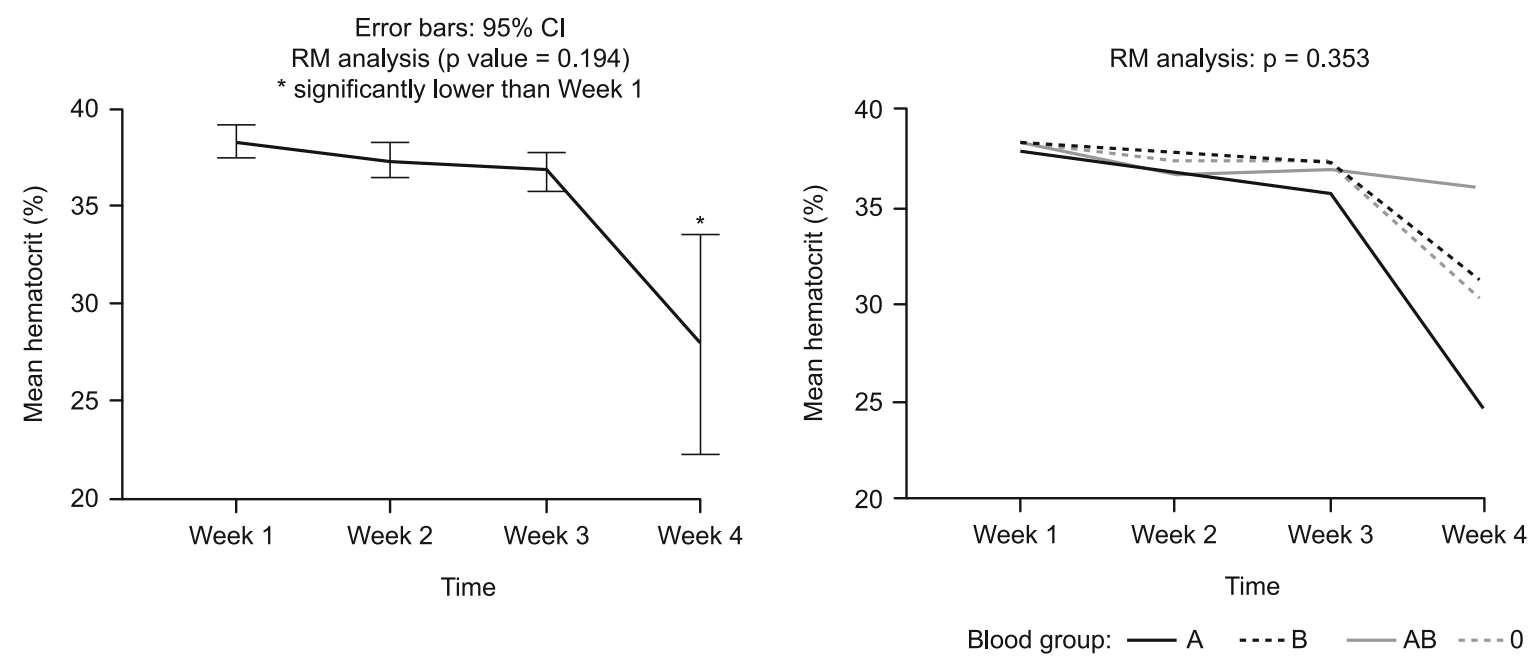

Fig. 6. The changes of HCT level during four weeks evaluation (left) and its association with ABO blood group (right)
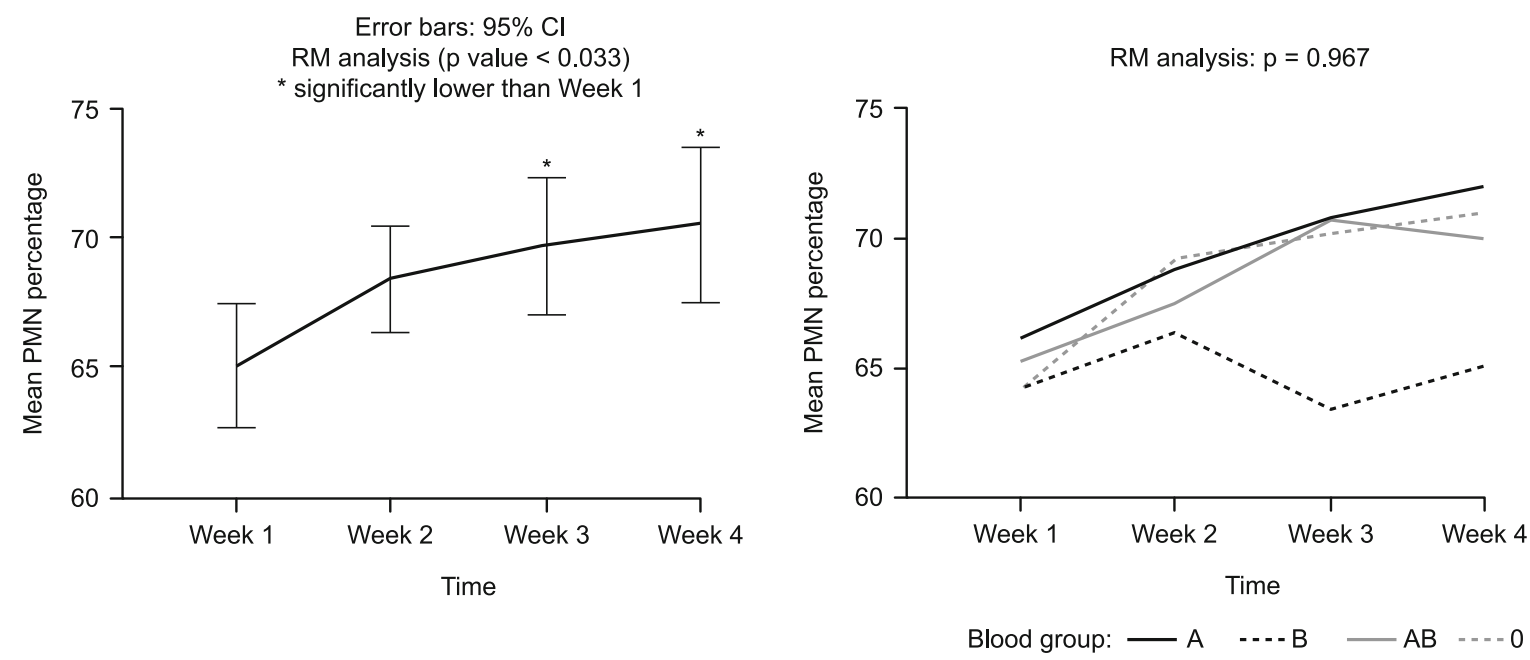

Fig. 7. The changes of PMN percentage during four weeks evaluation (left) and its association with ABO blood group (right) 


\section{Lymphocytes percentage}

A repeated measures ANOVA with a Greenhouse-Geisser correction showed that the lymphocytes percentage decreased ( $\mathrm{p}$ $<0.001$ ) during the time course (Fig. 4), but this reduction was not associated $(\mathrm{p}=0.280)$ with blood groups (Fig. 2). The mean Lymphocytes counts of each blood group were not significantly different compared with other blood groups in the same weeks.

\section{HB and HCT level}

A repeated ANOVA measurements with a Greenhouse-Geisser correction showed that the changes in HB level during radiotherapy were not statistically significant $(\mathrm{p}=0.167)$ (Fig. 5). Also, Figure 5 shows that the changes in HB levels of different blood groups which were not statistically associated with time $(p=0.236)$, and one-way ANOVA showed that the level of HB is not significantly different in blood groups $(\mathrm{p}=0.580)$. Also data showed that the changes in HCT level during radiotherapy were not statistically significant $(p=0.194)$ (Fig. 3). Also, as the Figure 6 shows the changes in HCT levels of different blood groups were not statistically associated with time $(p=0.353)$. But the one-way ANOVA showed that the HCT percentage in week 4 is lower than the other weeks ( $p<0.001$ for all).

\section{PMN percentage}

A repeated measurements ANOVA analysis showed that the PMN percentage has significantly changed during radiation therapy with an increasing trend $(p=0.033)$. But, the effect of blood groups on the changes of PMN percentage during the time course were not significant ( $p=0.967$ ) (Fig. 7). The one-way ANOVA test showed that the mean of PMN percentage at week 1 was significantly lower than at 3 and four weeks ( $\mathrm{p}$ value of 0.045 and 0.019 , respectively).

\section{Discussion}

In this observational study, our results showed that there is no significant change in RBC counts during radiotherapy which is in agreement with the previous studies and it refers to the fact that radiation damages the nucleus and RBC's nature exclude them from this fact (19) and also their lifespan are longer than the time course of this study. However, the effect of irradiation on RBC counts may be revealed in long-term period because of higher radio sensitivity of their progenitor stem cells (20). It needs a large sample size and a longer follow up period with cellular examinations for evaluating RBC's vestiges as a factor impressionable to irradiation. Our analysis showed the changes of RBC count during radiotherapy were not associated with $\mathrm{ABO}$ blood groups.

In addition, the results showed that the HB level changes are not significant during the course of radiotherapy which confirms the results of Geinitz et al (8) and there was no statistically significant association between HB level and blood group. Moreover, Sasai et al showed that patient with HB level over $11 \mathrm{~g} / \mathrm{dl}$ could have a longer survival period (13), but Bishop et al concluded that blood transfusion is not recommended if there is no clear evidence of benefit (10). It has been shown that the HB changes are a determinant for cancer patient quality of life (22). HB as a factor which plays a role in oxygen delivery to the tissues and could be important in clinical outcomes of radiotherapy because the oxygen is one of the most important modulating factors which improves the radiation damages and could sensitize the tissue. Furthermore, our data showed that the platelet counts were decreased at weeks 2, 3 and four compared to the time before starting the treatment process which is pointing out to the fact that their lifespan is 9-10 days (23). The mean of PLT count in each blood group was not significantly different to other blood groups which implies that the effect of radiation on PLT might be independent of the effect of ABO blood group and the repeated PLT counts analysis showed that PLT counts and blood group are not significantly associated with time.

Lymphocytes are one of the most radiosensitive cells of the body and are used in radiation biodosimetry (21). The lymphocyte counts in our study were decreased just after irradiation which confirms the high radiosensitivity of these cells which is consistent with Geinitz et al study (8). This immediate effect of irradiation on lymphocyte count could be a result of apoptosis of mature cells and also high radio sensitivity of their progenitor stem cells which reduce their bone marrow production (20). The mean lymphocytes counts of each blood group were not significantly different to the others in each week implying that these cells are radiosensitive in all individuals.

PMNs changes in acute irradiation are different, and an increase maybe occurs first and then the counts decrease (20). In this investigation, the PMN count did not decrease after four weeks since irradiation which could be the result of fractionation besides local irradiation in radiotherapy.

Our data showed that WBC counts decreased significantly two weeks after irradiation onset, suggesting radiosensitivity of different subsets of these blood cells. The mean WBC count of each blood group was meaningfully different, and the reduction of WBCwas significant in A and O blood groups. Some other studies also have shown an association between ABO blood groups and radiation effects. Habibi et al reported that patients with A blood group could be the most vulnerable to radiation-induced nausea and vomiting (22). Elahimaneshet alreported that $\mathrm{A}^{+}$and $0^{+}$blood groups are more and less radiosensitive than other blood groups (15) that is in agreement with our results. Also, Khosravifarsani et al reported that there is an association between $\mathrm{Rh}$ factor and radiosensitivity (23) which suggests that genetic factors including ABO blood groups should be taken into account in individualization of radiotherapy. And could be a very simple and achievable factor predicting patient's response/adverse reaction induced by irradiation in radiotherapy for cancer treatment or also use radionuclide for diagnostic intends.

The changes in blood cell counts in our study were different in the outcome for single acute dose and chronic exposure. Our results in this observational study showed promising association between $\mathrm{ABO}$ blood groups and some changes in blood cell counts and other hematological factors in cancer patients and more studies which address the need for more studies with a large sample size to verify the $\mathrm{ABO}$ blood group as a new predictive factor in individual radiotherapy are needed. 


\section{References}

1. Formenti SC, Demaria S. Systemic effects of local radiotherapy. The Lancet Oncol 2009; 10 (7): 718-726.

2. Tayebi, M, Shabestani Monfared A, Moslemi D. A 10 Year Survey of Cancer in Patients Who Referred to Shahid Rajai Radiotherapy Center in North of Iran (2000-2009). J Babol Univ Med Sci 2012; 14 (6): 97-101.

3. Rashedi J, Akbarzadeh M, Ajami Khiyav H, Haiaty S, Vahedian V, Hasanzadeh $\mathbf{O}$ et al. The role of folic acid in carcinogenesis, diagnosis, and treatment of cancer. Internat J Biomed Publ Health 2018; 1 (2): $115-122$.

4. Gregoire V, Langendijk JA, Nuyts S. Advances in Radiotherapy for Head and Neck Cancer. J Clin Oncol 2015.

5. Erdemli C, Omeroglu S, Sirav B, Colbay M, Seyhan N, Ozkan S et al. Effects of $2100 \mathrm{MHz}$ radio frequency radiation on ductus epididymis tissue in rats. Bratisl Lek Listy 2017; 118 (12): 759-764.

6. Tuohinen S, Turpeinen A, Skytta T, Kellokumpu-Lehtinen PL. Cardiac effects of radiation therapy. Duodecim; laaketieteellinen aikakauskirja 2015; 131 (5): 433-440.

7. Esmaeeli Dafchahi A, Pouladian M, Shabestani Monfared A, Mahdavi SR, Moslemi D. A Genetic Algorithm and Neural Network Hybrid Model to Predict Lung Radiation-induced Pneumonitis in Breast Radiotherapy (A simulation Study). J Babol Univ Med Sci 2014; 16 (1): 7.

8. Geinitz H, Zimmermann FB, Stoll P, Thamm R, Kaffenberger W, Ansorg K et al. Fatigue, serum cytokine levels, and blood cell counts during radiotherapy of patients with breast cancer. Internat J Radiat Oncol Biol Phys 2001; 51 (3): 691-698.

9. Borzoueisileh S, Monfared AS, Abediankenari S, Mostafazadeh A, Khosravifarsani M. The effects of residence duration in high background radiation areas on immune surveillance. J Natural Sci Biol Med 2013; 4 (1): 218-222

10. Chen K, Xie L, Zhangping, Yao W, Wen Z, Yan Z. Effect of radiation with $60 \mathrm{Co}$ on RBC membrane elastic shear modulus and membrane viscosity. J Biomed Engineering 2001; 18 (2): 206-209, 213.

11. Bishop AJ, Allen PK, Klopp AH, Meyer LA, Eifel PJ. Relationship between low hemoglobin levels and outcomes after treatment with radiation or chemoradiation in patients with cervical cancer: has the impact of anemia been overstated? Internat J Radiat Oncol Biol Phys 2015; 91 (1): 196-205.
12. Amorino GP, Lee H, Holburn GE, Paschal CB, Hercules SK, Shyr $\mathbf{Y}$ et al. Enhancement of tumor oxygenation and radiation response by the allosteric effector of hemoglobin, RSR13. Radiat Res 2001; 156 (3): 294-300.

13. Sasai K, Ono K, Hiraoka M, Tsutsui K, Shibamoto Y, Takahashi $\mathbf{M}$ et al. The effect of arterial oxygen content on the results of radiation therapy for epidermoid bronchogenic carcinoma. Internat J Radiat Oncol Biol Phys 1989; 16 (6): 1477-1481.

14. Gates MA, Wolpin BM, Cramer DW, Hankinson SE, Tworoger SS. ABO blood group and incidence of epithelial ovarian cancer. Internat J Cancer 2011; 128 (2): 482-486.

15. Elahimanesh F, Monfared AS, Khosravifarsani M, Niaki HA, Abedian Z, Hajian-Tilaki K et al. Is Radiosensitivity associated to different types of blood groups? (A cytogenetic study). Internat J Mol Cell Med 2013; 2 (3): 131.

16. Louagie H, Van Eijkeren M, Philippe J, Thierens H, de Ridder L. Changes in peripheral blood lymphocyte subsets in patients undergoing radiotherapy. Internat J Radiat Biol 1999; 75 (6): 767-771.

17. Hirst DG. Anemia: a problem or an opportunity in radiotherapy? Internat J Radiat Oncol Biol Phys 1986; 12 (11): 2009-2017.

18. Ghasemi S, Shabestani Monfared A, Borzoie sile S, Zabihi E, Amiri M, Abedian S. Predicting Factors of Radiosensitivity in Individual Radiotherapy. J Babol Univ Med Sci 2015; 17 (10): 67-73.

19. Button L, DeWolf W, Newburger P, Jacobson M, Kevy S. The effects of irradiation on blood components. Transfusion 1981; 21 (4): 419-426.

20. Dainiak N. Hematologic consequences of exposure to ionizing radiation. Exp Hematol 2002; 30 (6): 513-528.

21. Khosravifarsani M, Monfared AS, Elahimanesh F, Borzoueisileh S, Hajian-Tilaki K, Seyfizadeh $N$ et al. Is there association between handedness and radiosensitivity in breast cancer women? Med Oncol (Northwood, London, England) 2012; 29 (4): 2552-2555.

22. Habibi M, Namimoghadam A, Korouni R, Fashiri P, Borzoueisileh $\mathrm{S}$, Elahimanesh $\mathbf{F}$ et al. Radiation-induced nausea and vomiting: Is ABO blood group as important as radiation and patient-related factors? An observational study. Medicine 2016; 95 (31).

23. Khosravifarsani M, Monfared AS, Borzoueisileh S. Rh factor is associated with individual radiosensitivity: A cytogenetic study. Electronic Phys 2016; 8 (8): 2828. 